\title{
EFEITO DE FERTILIZANTES FOSFATADOS NA CULTURA DA CROTALÁRIA (1)
}

\begin{abstract}
ANTONIO LUIZ DE BARROS SALGADO (2), ANISIO AZZINI ( 2 ), Seçāo de plantas Fibrosas, CELI TEIXEIRA FEITOSA (2), Seção de Fertiliadade do solo e Nutriçāo de Plantas, ARMANDO PETTINELLI, Estaçāo Experimental de Tatui, e GUIDO DE SORDI, Estaçāo Experimental de Ribeirão Preto, Instituto Agronômico.
\end{abstract}

\section{RESUMO}

No presente trabalho são apresentados e discutiàos os resultados obtidos em seis experimentos de campo, em que se procurou estudar a resposta da crotaliária (Crotalaria juncea L.) a diversos adubos fosfatados, em ciferentes tipos de solo e regiöes paulistas, considerando-se a produção de massa verde e de sementes. Esses adubos, sempre acompanhados de nitrogênio e potássio, foram: superfosfato simples, superfosfato triplo, fosfato-de-araxá, termofosfato, farinha de ossos degelatinada e Yoorin. Os resultados dos experimentos revelam que os adubos fosfatados não apresentaram significância estatística sobre a produção de massa verde e sementes. Mesmo assim, convém ressaltar a posiçāo de destaque que alcançou em vários experimentos (Tatuí. Ribeirão Preto e Campinas) a utilização de farinha de ossos degelatinada na produção média de massa verde.

\section{INTRODUÇ̃̃O}

A cultura da crotalária (Crotalaria juncea L.), para fins de exploração de fibras destinadas à indústria de papéis finos, encontra praticamente em todas as zonas paulistas, exceto na Região Sul e no Vale do Ribeira, condições bastante satisfatórias de clima e solo para seu desenvolvimento.

(i) Recebido para publicação a 23 de abril de 1981 .

(2) Com bolsa de suplementação do Conselho Nacional de Desenvolvimento Cientifico e Tecnológico (CNPc...). 
Seu cultivo em São Paulo se vem mantendo constante quanto à área cultivada e produtividade. Entretanto, o interesse pela cultura como planta fibrosa começa a despertar em outras regiões do País. Além disso, essa leguminosa é a mais eficiente quanto à precocidade, na produção de massa incorporável e como fixadora de nitrogênio, quando utilizada como adubo verde.

A consulta da literatura revela não ter sido dos maiores o número de pesquisadores que se preocuparam com o problema da adubação da Crotalaria juncea $L$.

SALGADO et alii ( *), estudando o efeito da adubação NPK em diferentes tipos de solos e locais para a cultura da crotalária, observaram que houve reação favorável quando se utilizou fertilizante fosfatado e que uma adubação completa não era desaconselhável para os solos mais carentes.

SALGADO et alii (4), pesquisando o efeito da adubação NPK e calagem sobre a produção de massa verde e de sementes, observaram que o efeito do fósforo foi significativo em solos com menor teor do elemento e que houve efeito altamente positivo com o emprego do calcário.

O objetivo deste trabalho foi estudar o efeito de adubação fosfatada, quando se compararam diversos adubos, na produção de massa verde e de sementes da cultura da Crotalaria juncea L.

\section{MATERIAL E MÉTODOS}

Os experimentos foram realizados nos anos agrícolas de 1971/72 e 1972/73, nas Estações Experimentais de Tatuí (Latossolo Roxo), Ribeirão Preto (Latossolo Roxo) e Campinas (Latossolo Roxo, série Chapadāo), pertencentes ao Instituto Agronômico do Estado de São Paulo. no quadro 1 .

As características químicas das áreas utilizadas encontram-se repetições.

O delineamento experimental foi de blocos ao acaso, com cinco

As parcelas foram constituídas por dez linhas espaçadas de $0,20 \mathrm{~m}$, sendo oito úteis e duas marginais, desprezando-se $0,50 \mathrm{~m}$, em cada extremidade das linhas.

Os adubos fosfatados foram aplicados na dose de $60 \mathrm{~kg} / \mathrm{ha}$ de $\mathrm{P}_{2} \mathrm{O}_{5}$ total em presença de nitrogênio e potássio.

(*) SALGADO, A. L, B.; AZZINI, A.; FEITOSA, C. T.; PETTINELLI, A. Efeitos da adubaçáo NPK e calagem sobre a produção de massa verde e sementes de crotalária. (No prelo.) 
QUADRO 1. Características químicas das áreas utilizadas para experimentos de adubação fosfatada na cultura da Crotalaria juncea L.

\begin{tabular}{|c|c|c|c|c|c|c|c|}
\hline \multirow{2}{*}{ Local } & \multirow{2}{*}{ Ano } & \multirow{2}{*}{$\mathrm{pH}$} & \multirow{2}{*}{$\mathrm{C}$} & $\begin{array}{c}\mathrm{PO}^{3}- \\
4 \\
\end{array}$ & $\mathrm{Ca}$ & $+\mathrm{Mg}^{2+}$ & $\mathrm{Al3+}$ \\
\hline & & & & \multicolumn{4}{|c|}{ e.mg/100ml de T.F.S.A. } \\
\hline & & & $\%$ & & & & \\
\hline \multirow[t]{2}{*}{ Tatuỉ } & $71 / 72$ & 5,90 & 1,70 & 0,27 & 0,70 & 4,30 & - \\
\hline & $72 / 73$ & 5,60 & 1,50 & 0,07 & 0,34 & 3,60 & 0,60 \\
\hline \multirow[t]{2}{*}{ Ribeirão Preto } & $71 / 72$ & 5,70 & 2,30 & 0,07 & 0,26 & 3,50 & 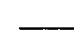 \\
\hline & $72 / 73$ & 5,60 & 2,00 & 0,02 & 0,12 & 2,90 & - \\
\hline \multirow[t]{2}{*}{ Campinas } & $71 / 72$ & 5,90 & 2,00 & 0,02 & 0,15 & 3,70 & - \\
\hline & $72 / 73$ & 5,60 & 2,00 & 0,03 & 0,26 & 5,20 & - \\
\hline
\end{tabular}

Foram comparados os seguintes fertilizantes fosfatados: superfosfato simples, $22 \%$ de $\mathrm{P}_{2} \mathrm{O}_{5}$; superfosfato triplo, $40 \%$ de $\mathrm{P}_{2} \mathrm{O}_{5}$; fosfato-de-araxá, 28\% de $\mathrm{P}_{2} \mathrm{O}_{5}$; termofosfato Akenaka, $19 \%$ de $\mathrm{P}_{2} \mathrm{O}_{5}$; farinha de ossos degelatinada, $23 \%$ de $\mathrm{P}_{2} \mathrm{O}_{\overline{5}}$ e Yoorin, $19 \%$ de $\mathrm{P}_{2} \mathrm{O}_{\overline{5}}$.

O nitrogênio foi fornecido através de salitre-do-chile, com $16 \%$ de $\mathrm{N}$, na base de $75 \mathrm{~kg} / \mathrm{ha}$ do elemento e, o potássio, na forma de cloreto de potássio, com $60 \%$ de $\mathrm{K}_{2} \mathrm{O}$ na dose de $60 \mathrm{~kg} /$ ha de $\mathrm{K}_{2} \mathrm{O}$.

A mistura dos fertilizantes minerais contendo $\mathrm{N}, \mathrm{P}$ e $\mathrm{K}$ fọi incorporada ao solo, após ser distribuída uniformemente em toda a área de cada canteiro, antes da semeação.

Os experimentos foram instalados em outubro/novembro, na época recomendada para plantio, segundo LOVADINI et alii (2).

Foi empregado nos experimentos o cultivar comum, de longa data cultivado como adubo verde e produtor de fibras.

Cada linha das parcelas experimentais recebeu 9 gramas de sementes, numa média de 45 sementes por metro linear, distribuídas uniformemente no interior dos sulcos e cobertas com leve camada de terra.

A germinação das sementes deu-se em média entre quatro $\mathrm{e}$ seis dias após o plantio, de maneira uniforme em todos os experimentos.

Capinas manuais foram realizadas aproximadamente 30 dias após a germinação e repetidas quando necessário por mais uma ou duas vezes.

A colheita foi realizada com as plantas em plena maturação (sementes secas), decorridos aproximadamente 200 dias do plantio. 
Os caules foram ceifados bem rente ao solo e as sementes, extraídas, batendo-se as vagens sobre um encerado e abanando-se posteriormente para limpeza.

\section{RESULTADOS E DISCUSSÃo}

\subsection{Efeito dos fertilizantes fosfatados}

A avaliação dos efeitos da aplicação dos fertilizantes fosfatados: superfosfato simples, superfosfato triplo, fosfato-de-araxá, termofosfato, farinha de ossos degelatinada e Yoorin, foi feita em relaçāo às testemunhas sem adubação e adubação mineral com nitrogênio e potássio na ausência de fósforo.

Para a avaliação da eficiência dos diversos fosfatados, foram tomadas as produções, em quilograma por hectare, de massa verde e de sementes.

No quadro 1, observa-se que, com exceção de Tatuí em 1971/72, os teores de fósforo variaram de 0,02 a $0,07 \mathrm{e} . \mathrm{mg} / 100 \mathrm{ml}$ de solo, considerados baixos; no entanto, não houve resposta para a aplicação dos fertilizantes fosfatados.

As análises de variância para todos os experimentos não apresentaram significância para os tratamentos; conseqüentemente, observa-se que não houve respostas significativas nas produções de Crotalaria juncea, devido às fontes de fósforo aplicadas nas diferentes localidades. Isso indica sua grande capacidade de aproveitamento de fósforo do solo, pelo seu sistema radicular ramificado e profundo.

Os trabalhos sobre a influência da adubação fosfatada na Crotalaria juncea são muito escassos na literatura: apenas SALGADO et alii $(*, 4)$ apresentaram trabalhos em que se estudou o efeito da adubação NPK sobre essa leguminosa, portanto, devem ser desenvolvidos novos experimentos a fim de que possam ser mais bem esclarecidos os efeitos dos fosfatos sobre sua produção de massa verde e sementes.

\subsubsection{Produção de massa verde}

Os resultados da produção de massa verde de Crotalaria juncea, expressa em quilograma por hectare, nas diferentes localidades, para os anos agrícolas de 1971/72 e 1972/73, assim como os resultados da análise da variância, constam respectivamente dos quadros 2 e 3 .

O efeito dos adubos fosfatados não apresentou significância estatística sobre a produção de massa verde, nos seis experimentos:

(\%) SAlGADO. A. L. B.; AZZINI, A.; FEITOSA, C. T.; PETTINELli, A. Efeitos da adubação NPK e calagem sobre a produção de massa verde e sementes de crotalária. (No prelo.) 


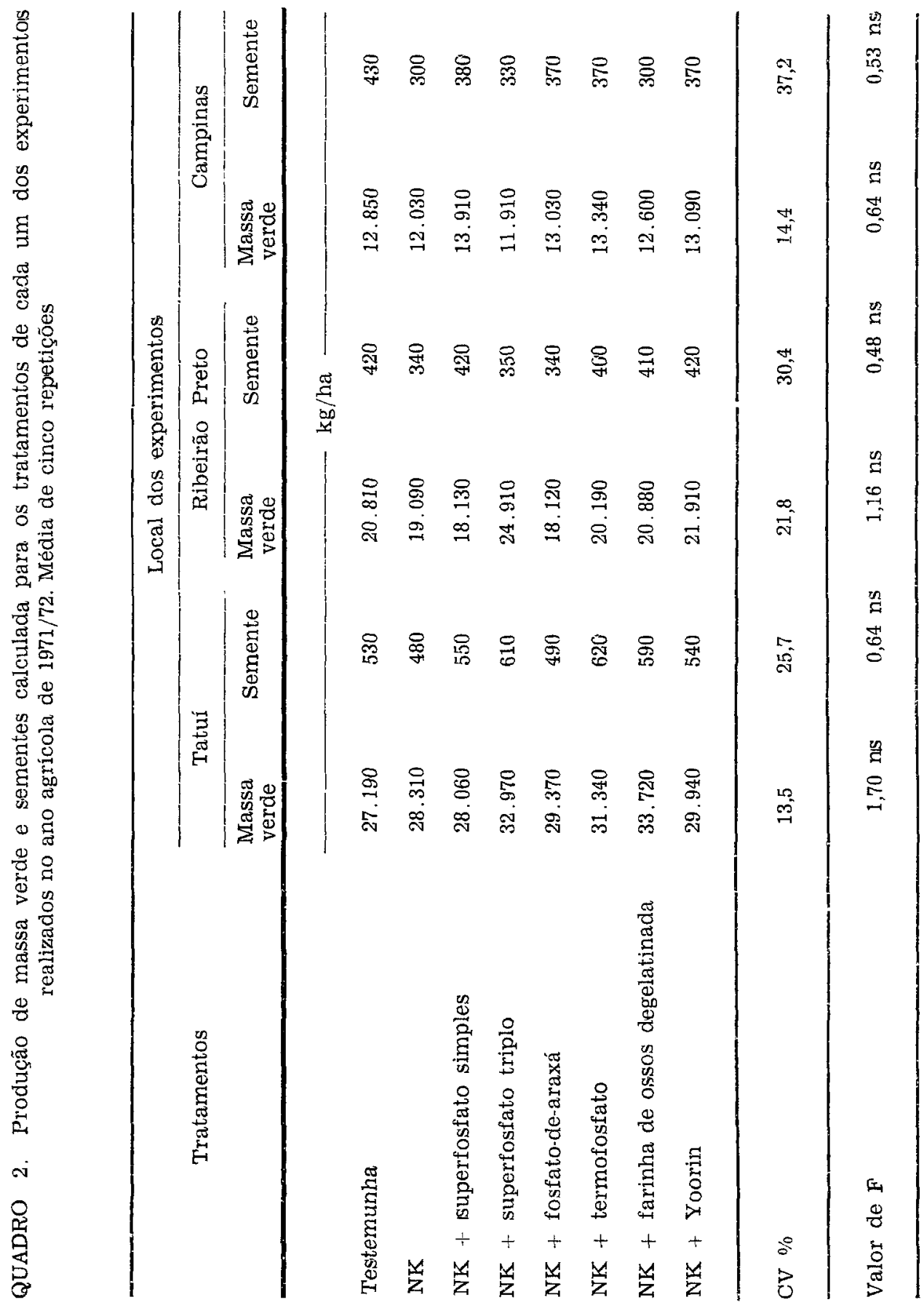




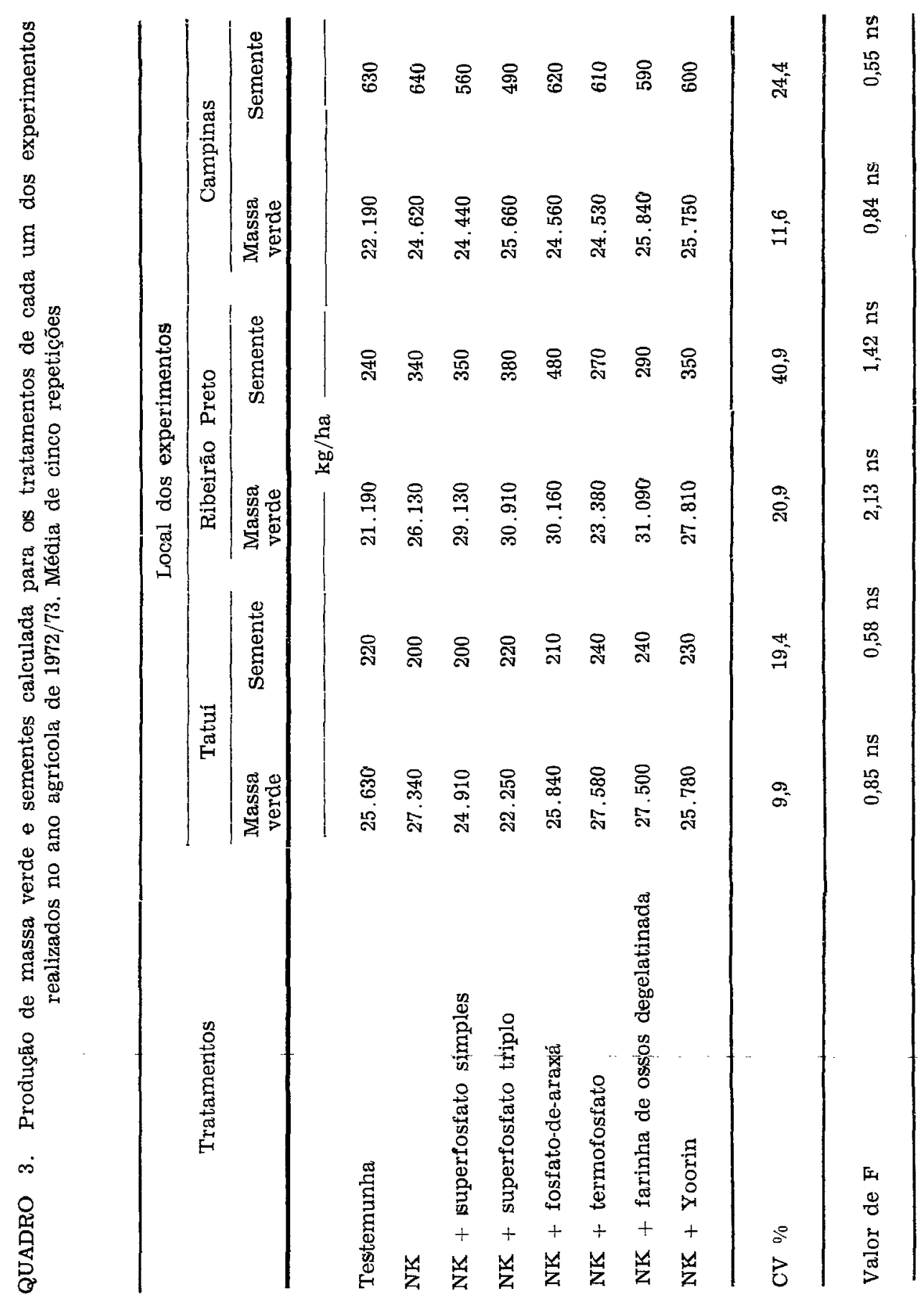


apesar de apresentar diferença percentual em alguns casos sobre a testemunha, principalmente quando da utilização da farinha de ossos degelatinada. A análise conjunta tratamento versus ano não apresentou significância para todos os locais estudados.

No experimento realizado em Tatuí, em 1971/72, mesmo não havendo efeito significativo na análise da variância, houve diferença percentual entre a utilização da farinha de ossos degelatinada e as testemunhas, $23 \%$ para o sem adubação e $19 \%$ para a adubação com nitrogênio e potássio, o que praticamente se repetiu no mesmo local no ano agrícola seguinte.

Em Ribeirão Preto, houve destaque para a utilização de superfosfato triplo e farinha de ossos degelatinada, superiores em mais de $30 \%$ sobre as testemunhas, nos dois anos agrícolas.

Em Campinas, a igualdade entre os tratamentos foi mais acentuada, mas a utilização de superfosfato simples, farinha de ossos degelatinada e Yoorin, apresentou ligeira vantagem sobre a testemunha sem adubação, em torno de $15 \%$, nos dois anos agrícolas.

\subsubsection{Produção de sementes}

Os resultados da produção de sementes de Crotalaria juncea, expressos em quilograma por hectare, nas diferentes localidades, para os anos agrícolas de 1971/72 e 1972/73, assim como os resultados da análise de variância para os respectivos experimentos, constam dos quadros 2 e 3.

o efeito dos adubos fosfatados não apresentou significância estatística sobre a produção de sementes; entretanto, em diferentes experimentos, a produção das testemunhas foi percentualmente maior que a dos tratamentos adubados.

A análise conjunta tratamento versus ano apresentou diferenças altamente significativas para a localidade de Tatuí, em cujos experimentos é que se observou diferença percentual favorável ao emprego de superfosfato triplo, termofosfato e farinha de ossos degelatinada.

\section{CONCLUSÕES}

Dos resultados dos experimentos relatados no presente trabalho, no qual foram estudados os efeitos de seis adubos fosfatados: superfosfato simples, superfosfato triplo, fosfato-de-araxá, termofosfato, farinha de ossos degelatinada e Yoorin, sobre a produção de massa verde e sementes de Crotalaria juncea L., podem-se tirar as seguintes conclusões : 
a) Os efeitos dos adubos fosfatados não apresentaram significância estatística sobre a produção de massa verde, nos seis experimentos realizados, apesar da marcante diferença percentual em alguns casos sobre as testemunhas.

b) O efeito dos adubos fosfatados não apresentou significância estatística sobre a produção de sementes, nos seis experimentos realizados; entretanto, em todos eles, houve acentuado aumento percentual sobre as testemunhas.

c) Mesmo não apresentando efeito significativo na análise da variância, convém ressaltar a posição de destaque alcançada em vários experimentos localizados em Tatuí, Ribeirão Preto e Campinas, pela utilızação da farinha de ossos degelatinada na produção de massa verde.

\section{SUMMARY}

\section{EFFECT OF PHOSPHATE FERTILIZERS IN SUNN HEMP CROP}

The objective of this work was to study the growth response of sunn hemp (Crotalaria juncea L.) to different phosphate fertilizers, in three locations. Six field experiments were carried out in the Experimental Stations of the Agricultural Institute of the State of São Paulo, Brazil, located in Tatuí, Ribeirão Preto and Campinas, during two following years, $1971 / 72$ and $1972 / 73$. The soils in those iocations corresponded to a Dusky Red Latosol. The treatments consisted of the following phosphate fertilizers: simple superphosphate, triple superphosphate, phosphate of Araxá, thermophosphate, steamed bone meal and Yoorin. Nitrogen and botassium fertilizers were also supplied in normal rates. Two checks were used, one without any fertilization and another with nitrogen and potassium fertilizers only. The experimental design consisted of randomized complete blocks with five replications. The results obtained showed higher green matter and seed yields, by the plants grown with steamed bone meal, in several experiments in all three locations. However, in the analysis of variance these differences were not statistically significant.

\section{REFERENCIAS BIBLIOGRAFICAS}

1. BRASIL. Ministério da Agricultura. Levantamento de reconhecimento dos solos do Estado de São Paulo. Rio de Janeiro, Centro Nacional de Ensino e Pesquisas Agronômicas, 1960. 634p. (Boletim do Serviço Nacional de Pesquisas Agronômicas, 12)

2. LOVADINT, L. A. C.; SALGADO, A. L. B. \& MIYASAKA, S. Efeito da época de plantio e da poda na produção de massa verde e sementes de Crotalaria juncea L. Bragantia, Campinas, 29:25-30, 1970.

3. MALAVOLTA. E. Manual de química agrícola: adubos e adubação. São Paulo, Ceres, $1959.487 \mathrm{p}$.

4 SALGADO, A. L. B.; AZZINI, A.; FEITOSA, C. T.; PETTINELLI, A. \& DE SORDI, G. Efeitos de adubação NPK na cultura da crotalária (Crotalaria juncea L.). Bragantia, Campinas, 41: 21-33, 1982. 